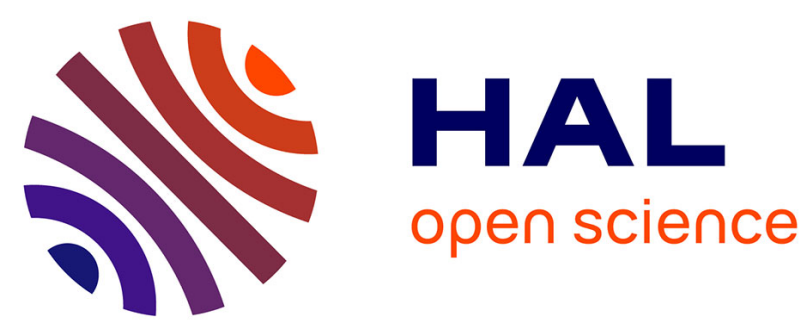

\title{
New acoustic resonator based on periodically poled transducer in lithium niobate or tantalate
}

\author{
F. Bassignot, G. Ulliac, E. Courjon, S. Ballandras, J.-M. Lesage
}

\section{To cite this version:}

F. Bassignot, G. Ulliac, E. Courjon, S. Ballandras, J.-M. Lesage. New acoustic resonator based on periodically poled transducer in lithium niobate or tantalate. Joint Conference on IEEE International Symposium on Applications of Ferroelectrics (ISAF/PFM)/ International Symposium on Piezoresponse Force Microscopy and Nanoscale Phenomena in Polar Materials, Jul 2011, Vancouver, Canada. pp.1-4, 10.1109/ISAF.2011.6013990 . hal-00651285

\section{HAL Id: hal-00651285 \\ https://hal.science/hal-00651285}

Submitted on 30 Apr 2021

HAL is a multi-disciplinary open access archive for the deposit and dissemination of scientific research documents, whether they are published or not. The documents may come from teaching and research institutions in France or abroad, or from public or private research centers.
L'archive ouverte pluridisciplinaire HAL, est destinée au dépôt et à la diffusion de documents scientifiques de niveau recherche, publiés ou non, émanant des établissements d'enseignement et de recherche français ou étrangers, des laboratoires publics ou privés. 


\section{New acoustic resonator based on periodically poled transducer in lithium niobate or tantalate}

\author{
F. Bassignot, G. Ulliac, E. Courjon, S. Ballandras \\ Institut FEMTO-ST \\ UMR 6174 CNRS-UFC-ENSMM-UTBM \\ 26 che. de l'épitaphe, 25000 Besançon, France \\ florent.bassignot@femto-st.fr
}

\author{
J.M. Lesage \\ CELAR \\ DGA \\ Rennes, France
}

\begin{abstract}
In this paper, we propose a new concept of acoustic resonator based on a waveguide structure. In the telecommunication market, composants used are indeed generally bases on Surface Acoustic Wave (SAW) or Bulk Acoustic Wave (BAW) devices. However, those systems present technological limits as short-circuits between the electrodes of the interdigital transducers (for SAW device) or the precise control of the piezoelectric material thick resonator (for BAW device). We suggest a new concept based on a periodically poled transducer (PPT) in a ferroelectric substrate $\left(\mathrm{LiNbO}_{3}\right.$ or $\mathrm{LiTaO}_{3}$ ), embedded between two guiding substrates in order to create an acoustic waveguide. Periodically poled transducers have been investigated recently as an alternative to classical inter-digital transducers for the excitation and detection of guided acoustic waves. A resonator operating at $131 \mathrm{MHz}$ has been successfully fabricated and used in order to stabilize an oscillator at this frequency. However, the developed resonator presents a significant thermal sensitivity. The following experiments have consisted in studying a Si/thinned PPT layer/Si structure in order to reduce the thermal sensitivity.
\end{abstract}

Resonator; inter-digital transducer; periodically poled transducer; lithium niobate; lithium tantalate; thermal

\section{INTRODUCTION}

The demand of acoustic wave devices in telecom as resonators or filters has generated a strong innovative activity. These components are usually based on surface or bulk acoustic wave technologie. However, those technologies are sensitive to the environment and presents some technological limits. Passive components using trapped acoustic waves are thus well-suited. We suggest an innovative solution in order to answer to the need of high frequencies sources (RF until X band domain). These sources indeed need spectral purity, shortterm stability and phase noise around the carrier wave. The purpose is to fabricate resonators based on the ultrasonic waves propagation through a waveguide. This resonator operates with a PPT inserted between two guiding substrates. A wave propagates without any acoustic losses and decreases exponentially in the structure (Fig. 1). This definition is similar in these interface waves [1]. Nevertheless, the principle is substantially different for various reasons. First, the transduction structure corresponds to a layer in which ferroelectric domains have been artificially structured as developed in [2-3-4]. Classical inter-digital transducers have been given up in this kind of structure because the bonding is difficult due to the electrode pattern. In this case, a polymer film is deposited between both substrates to be bonded in order to create an elastic link introducing important acoustic losses.

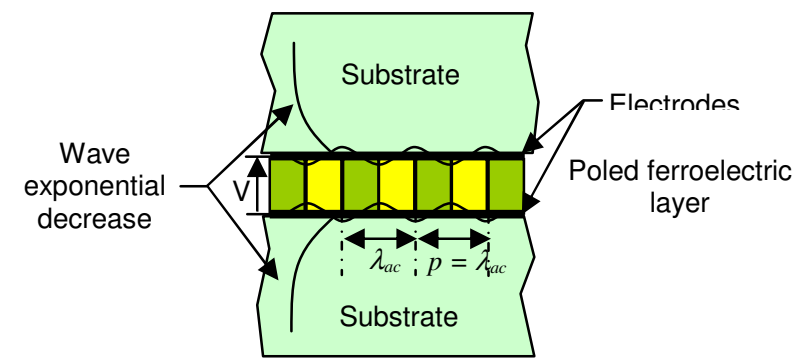

Figure 1. Scheme of the new concept waveguide based on PPT

In the first part, we present the simulation, the fabrication and the characterization of a PPT-based resonator operating at $131 \mathrm{MHz}$ with a Silicon $(\mathrm{e}=380 \mu \mathrm{m}) / \mathrm{LiNbO}_{3} \mathrm{PPT}(\mathrm{e}=500 \mu \mathrm{m}$, $\lambda=50 \mu \mathrm{m}) / \operatorname{Silicon}(\mathrm{e}=380 \mu \mathrm{m}) \quad$ structure. We present the resonator oscillation characteristics, more particularly the phase noise and the frequency stability. In a second part, we exhibit the advantages of thinning down the piezoelectric transducer in showing the dispersion properties analysis. We describe the fabrication with the home-made lapping and polishing process and the characterization of resonators based on thinned PPT in lithium niobate and tantalate. The fabrication of PPTs exhibiting poling periods of 5 to $200 \mu \mathrm{m}$, operating in the range $50 \mathrm{MHz}-1,3 \mathrm{GHz}$ has been achieved on 3 and 4 inch $500 \mu \mathrm{m}$ thick $\mathrm{LiNbO}_{3}$ and $\mathrm{LiTaO}_{3} \mathrm{Z}$-cut wafers. An oscillator using a $\mathrm{Si} / \mathrm{PPLN} / \mathrm{Si}$ resonator, exhibiting a $50 \mu \mathrm{m}$ period and a $500 \mu \mathrm{m}$ thick piezoelectric layer, has pointed out the concept feasibility and answers to scope statement. In fact, these resonators, with low insertion losses and a phase noise of $100 \mathrm{kHz}$ of the carrier wave controlled, less than $-160 \mathrm{dBc} / \mathrm{Hz}$, are well-suited for radar applications. However, the developed resonator presents a significant thermal sensitivity of $-50 \mathrm{ppm} / \mathrm{K}$. Thereby, the PPT dispersion properties analysis has shown an optimum thickness of the piezoelectric plate, corresponding to the maximal electromechanical coupling coefficient and a thermal sensitivity limited by guiding materials. Si/PPT/Si test vehicles, exhibiting a $50 \mu \mathrm{m}$ period and a piezoelectric layer thickness around $20 \mu \mathrm{m}$, have pointed out the existence of an isolated mode operating at frequencies near $110 \mathrm{MHz}$ for a $\mathrm{LiNbO}_{3} \mathrm{PPT}$ and near $90 \mathrm{MHz}$ with $\mathrm{LiTaO}_{3}$ PPT with a thermal sensitivity of around $-30 \mathrm{ppm} / \mathrm{K}$ equal to the silicon thermal sensitivity. 


\section{Si/THICK PERIODICALly POLED TRANSDUCER/Si-BASED RESONATOR: FABRICATION AND CHARACTERIZATION}

In this part, we will present the fabrication of the new waveguide resonator. We will detail particularly the poling step. After that, we will present some measurement (admittance and thermal sensitivity) of a resonator successfully achieved and we will compare them with the theoretical results using our finite and boundary element (FEM-BEM) simulation tool. Finally, we will show the fabrication and characterization of an oscillator with this resonator at $131 \mathrm{MHz}$.

\section{A. Fabrication}

The fabrication of acoustic waveguides based on PPTs consists in bonding a silicon wafer on each side of a periodically poled wafer. We present the flowchart which summarizes the different steps of fabrication in Fig.2a. In that purpose, a $500 \mu \mathrm{m}$ thick $\mathrm{Z}$ cut lithium niobate wafer is poled and bonded on a (100) 3" or 4" doped silicon wafer using a wafer bonding technique developed in our group based on a metal-metal adhesion at room temperature promoted by a high pressure applied to the material stack. A SEM view of this stack is presented in Fig.2b. The structure has been etched in hydrogen fluoride (HF) solution in order to observe the domain alternation.
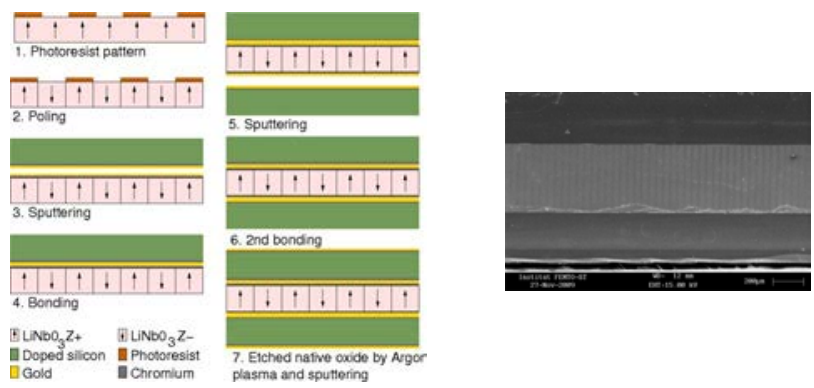

(a)

(b)

Figure 2. $\quad$ (a) Flowchart of the Si/TPP/Si resonator fabrication (b) Double bonding of a $500 \mu \mathrm{m}$ thick lithium niobate PPT with two silicon wafers using room temperature $\mathrm{Au} / \mathrm{Au}$ bonding process

As previously presented [5], we have performed our experiments on a dedicated poling bench (Fig. 3) which can control the poling of thick $(500 \mu \mathrm{m})$ optical quality Z-cut $\mathrm{LiNbO}_{3}$ plates.

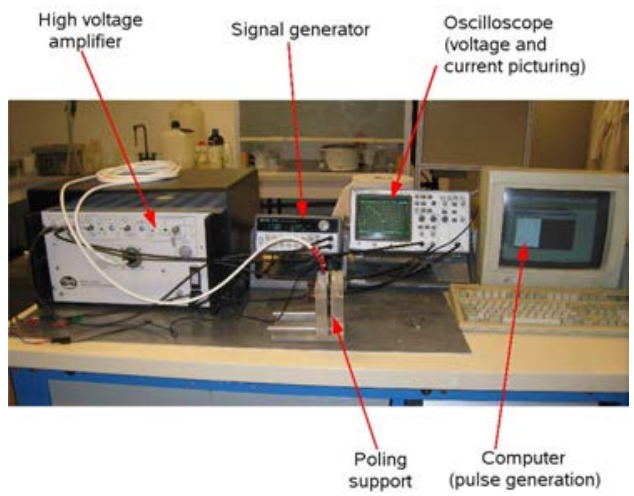

Figure 3. Poling bench
The poling mainly consists of a high voltage amplifier used to submit the wafer to an electric field strong enough to invert the negative poling of the material. The domains to be poled are defined using a photo-resist pattern on top of a plate surface. The coercive field of the lithium niobate is $21 \mathrm{kV} / \mathrm{mm}$. The plate is held in a Polymethyl methacrylate (PMMA) mounting by means of two O-ring joints which create two cavities full filled by a saturated lithium chloride solution used as a liquid electrode (as it is shown in the scheme of Fig.4).

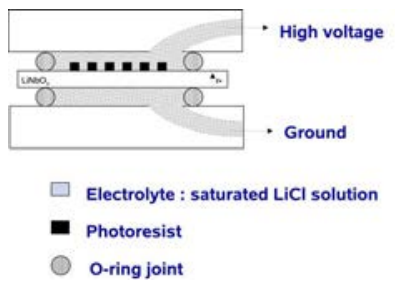

Figure 4. Principle of the substrate support of the poling bench

The high poling voltage is applied to the plate following the sequence shown in Fig.5. This sequence is designed to favor the domain nucleation, to stabilize the inverted domains (i.e. to avoid back-switching of the domains) and to avoid electrical breakdowns [6]. The poling process is monitored thanks to the measurement of the electric current crossing the wafer during the sequence. The signature of a successful domain inversion corresponds to a voltage dropping while a current discharge occurs simultaneously (see Fig.5).

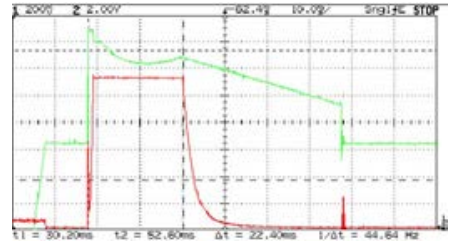

Figure 5. Domain inversion monitoring: probed high voltage applied on the wafer (green curve, poling sequence) and resulting crossing current (red curve). Voltage and current gain are respectively $1 \mathrm{~V} / 5000 \mathrm{~V}$ and $1 \mathrm{~V} / 5 \mathrm{~mA} .1^{\text {st }}$ step : the applied electric field is smaller than the coercive limit, to prepare the sample for the nucleation step. $2^{\text {nd }}$ step : the applied field overcomes the coercive limit, yielding nucleation and consequently poling (this step lies between the 2 dashed cursors). $3^{\text {rd }}$ step : linear decrease of the field to end-up the nucleation (self-termination step, exponential decrease of the current). $4^{\text {th }}$ step : stabilization of the poling by applying a field smaller than the coercive limit

We have observed on the fabrication PPT, an over poling effect due electric field lines (edge effect). This phenomenon is annoying when we reduce the PPT period because we obtain a total poling of the substrate. We have thus thinned the ferroelectric material. We use home-made lapping and polishing techniques to thin the material to about $270 \mu \mathrm{m}$-thick before the poling step. The aim is the reduce in poling voltage applied on the substrate. We have achieved the fabrication of a $5 \mu \mathrm{m}$-period PPT exciting waves up to $1 \mathrm{GHz}$ with a $\mathrm{LiNbO}_{3}$ wafer. The poling can be easily controlled by a simple optical post-observation, as it generates a contrast at the edge of the poled domains (see Fig.6). The evidence of contrast modification in the vicinity of the poled domain walls at the poled strip edge (the whole plate is $\mathrm{Z}+$ oriented, the poled strips are $\mathrm{Z}$ - oriented) may be due to diffusion effects. 


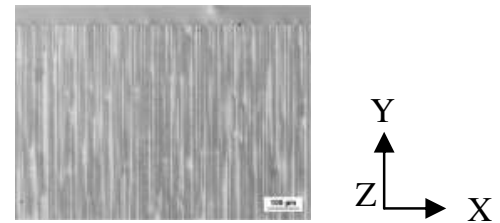

Figure 6. Optical verification of the poling efficiency, case of a $5 \mu \mathrm{m}$ period device, evidence of contrast changes between $\mathrm{Z}+$ (native polarization) and $\mathrm{Z}$ - (switched polarization) domains.

\section{B. Experimental results compared with theoretical analysis}

Operational $50 \mu \mathrm{m}$ period test vehicles have been achieved using doped silicon wafers to ease the electrical contact and tested by means of a network analyzer yielding $\mathrm{Si} / \mathrm{PPT} / \mathrm{Si}$ devices responses.

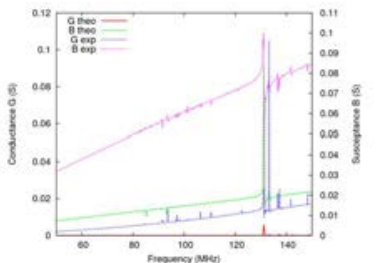

(a)

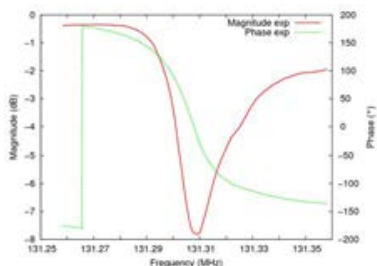

Figure 7.

(a) Theoretical and experimental admittances of a $\mathrm{Si} / \mathrm{LiNbO}_{3}(500 \mu \mathrm{m}) / \mathrm{Si}$ structure and (b) evolution of the dynamic of the coefficient $S_{11}$ and the phase rotation versus frequency for the longitudinal mode

Theoretical and experimental admittances fit well and allow for identifying a main contribution corresponding to a guided longitudinal mode at $131 \mathrm{MHz}$ (Fig.7a). The corresponding phase velocity is very close to the one obtained with a single PPT (i.e $6500 \mathrm{~m} . \mathrm{s}^{-1}$ ) [7]. This resonator operating near $131 \mathrm{MHz}$ exhibits a quality factor of 13000 and an electromechanical coupling $\mathrm{ks}^{2}$ of $0.25 \%$ (twice higher than a SAW quartz resonator). The corresponding phase rotation $\left(320^{\circ}\right)$ and the dynamic of its electrical reflection coefficient $S_{11}$ equal to $-8 \mathrm{~dB}$ make it compatible with oscillator applications (fig.7b).

A specific printed circuit has been implemented for phase noise tests with our $\mathrm{Si} / \mathrm{LiNbO}_{3}$ PPT $(e=500 \mu \mathrm{m}, \lambda=50 \mu \mathrm{m}) / \mathrm{Si}$ resonator and the Colpitts oscillator (Fig.8a). The phase noise of the oscillator at $100 \mathrm{kHz}$ from the carrier shows a value less than $-160 \mathrm{dBc} / \mathrm{Hz}$ (Fig.8b), which can be honestly compared with other acoustic wave oscillators at such frequency, accounting for the fact that the device was excited with a quite low signal level $(-6 \mathrm{dBm})$.

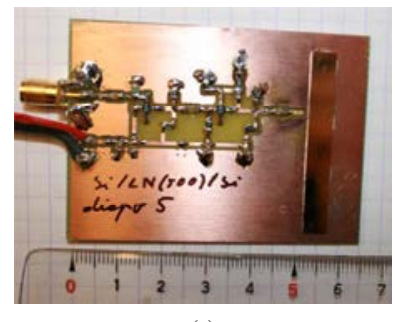

(a)

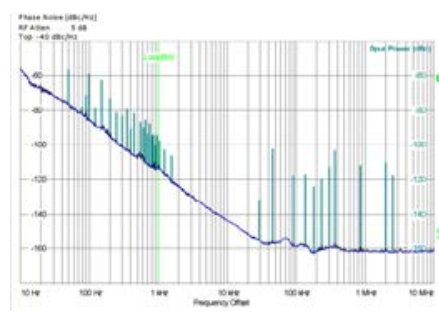

(b)
Figure 8. $\quad$ (a) Test vehicule and (b) phase noise of the $131 \mathrm{MHz}$ oscillator stabilized by a waveguide resonator $\left(\mathrm{Si} / \mathrm{LiNbO}_{3} \mathrm{PPT} / \mathrm{Si}\right)$
We have also studied the stability of this oscillator, and we have obtained a frequency stability of $10^{-9}$ at less than $1 \mathrm{~s}$ (Fig.9a). This experiment has been performed at room temperature without any thermal compensation.

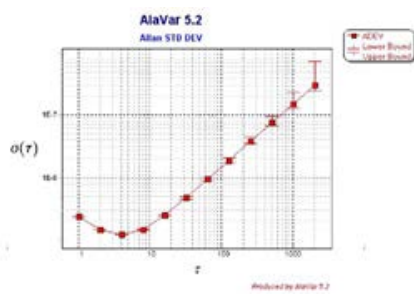

(a)

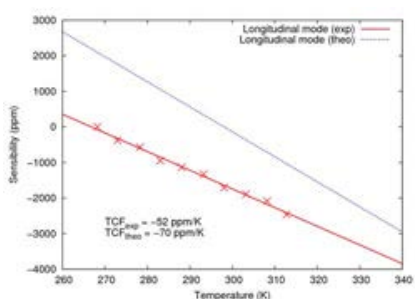

(b)
Figure $9 . \quad$ (a) Frequency stability curve of a $131 \mathrm{MHz}$ oscillator and (b) Temperature drift for the longitudinal mode

The frequency drift of this longitudinal mode at $131 \mathrm{MHz}$ versus the temperature for a $50 \mu \mathrm{m}$ period structure is reported in Fig.9b. We have found frequency variations of $-52 \mathrm{ppm} / \mathrm{K}$ for the longitudinal mode for a thick $\mathrm{LiNbO}_{3}$ wafer bonded between two Silicon. The theory predicts a value higher than the experience. However, both results are in the same order. The thermal sensitivity of the stack is lower to the one of a single PPT $(\mathrm{TCF}=-80 \mathrm{ppm} / \mathrm{K})$. As the $\mathrm{TCF}$ of the silicon material is about $-30 \mathrm{ppm} / \mathrm{K}$ [8], when the PPT is reported on silicon, the thermal sensitivity of the stack is reduced. If the thickness of the ferroelectric material decreases, the TCF will tend to the silicon one.

The further experiments consist in studying a $\mathrm{Si} /$ thinned PPT layer/Si in order to obtain a monomode acoustic wave device with an isolated mode exhibiting a low thermal sensitivity.

\section{Si/ THINNED PERIODICALly POLED TRANSDUCER/SI- BASED WAVEGUIDES}

The study of the dispersion properties enables to define a specific configuration using a thinned PPT layer [5]. Interesting guidance properties have been obtained for a ratio between the thickness of the layer and the inverted domains period lower than 1 and as a result the maximum of the electromechanical coupling is obtained for a $15-25 \mu \mathrm{m}$ thick $\mathrm{LiNbO}_{3}$ or $\mathrm{LiTaO}_{3}$ layer for a $50 \mu \mathrm{m}$ period. The global flow-chart to fabricate $\mathrm{Si} /$ thinned PPT layer/Si acoustic waveguides is approximately the same than the process used for Si/thick PPT/Si (Fig.2a). The extra step consists in lapping and polishing the PPT in order to obtain a thinned PPT layer of about $15-25 \mu \mathrm{m}$. Our lapping machine is presented in Fig.10a. Finally this stack ( $\mathrm{Si} /$ thinned PPT) is bonded on a second doped silicon wafer in order to define the desired compact structure $\mathrm{Si} / \mathrm{PPT} / \mathrm{Si}$. On figure $10 \mathrm{~b}$, we can see a SEM observation obtained for about a $20 \mu$ m-thick $\mathrm{LiNbO}_{3}$ layer confined between two silicon substrates. 


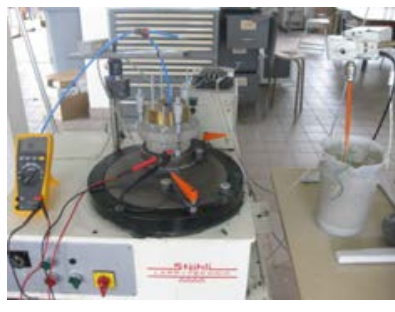

(a)

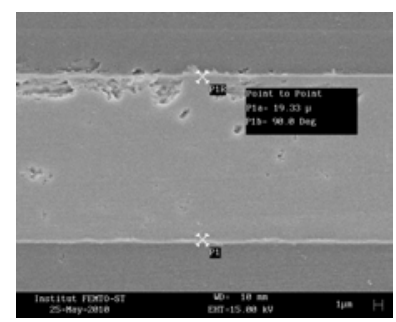

(b)
Figure 10.

(a) Photograph of the equipment used for lapping/polishing operations and (b) SEM view of a Si/thinned PPT/Si transducer

Operational test vehicles have been achieved using $\mathrm{LiNbO}_{3}$ and $\mathrm{LiTaO}_{3}$ wafers as poled ferroelectric layer. Experimental results of the Si/thinned PPT layer/Si devices with a $50 \mu \mathrm{m}$ period are reported in Fig.11. For both materials, only one contribution is observed: at $110 \mathrm{MHz}$ for a $\mathrm{LiNbO}_{3}$ layer (Fig.11a) and at $88 \mathrm{MHz}$ for a $\mathrm{LiTaO}_{3}$ layer (Fig.11b). Unfortunately, those monomode acoustic devices, due to a non homogenous thickness of the PPT layer along several millimeter long ferroelectric gratings, do not exhibit properties compatible with oscillator applications.

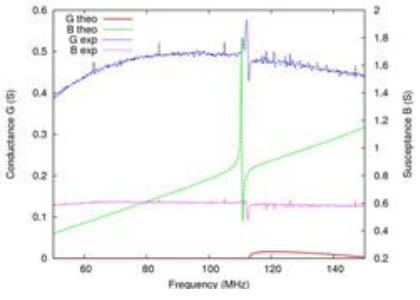

(a)

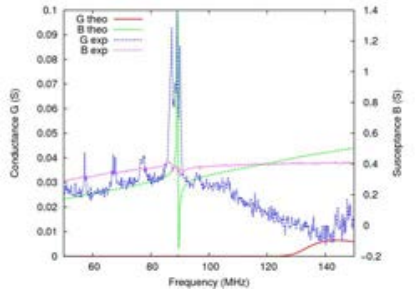

(b)
Figure 11. Theory/experitment assessment for a Si/thinned PPT/Si device for a $50 \mu \mathrm{m}$ poling period built on a Z-cut $\mathrm{LiNbO}_{3}$ plate $(20 \mu \mathrm{m})$ (a) and a Z-cut $\mathrm{LiTaO}_{3}$ plate $(20 \mu \mathrm{m})$ (b)

We have also studied the frequency drift of the isolated mode versus the temperature for a $50 \mu \mathrm{m}$ period structure (Fig.12). We have found frequency variations of $-33 \mathrm{ppm} / \mathrm{K}$ for the isolated mode for a $20 \mu \mathrm{m}$-thick $\mathrm{LiNbO}_{3}$ layer and of $31 \mathrm{ppm} / \mathrm{K}$ for a $20 \mu \mathrm{m}$-thick $\mathrm{LiTaO}_{3}$ layer. We point out that the simulation tends toward the experience when the ferroelectric layer thickness tends to zero micron. We can conclude that the TCF of a thinned PPT-based structure is limited by the thermal sensitivity of the silicon $(-30 \mathrm{ppm} / \mathrm{K}[8])$. Finally, if we choose an appropriate insensitive material as guiding substrate, we can obtain an insensitive resonator versus temperature.

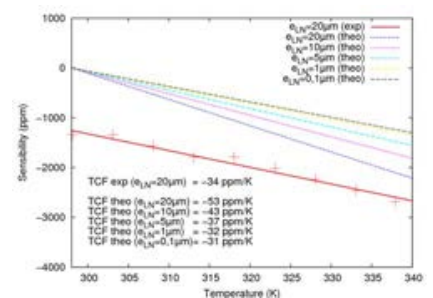

(a)

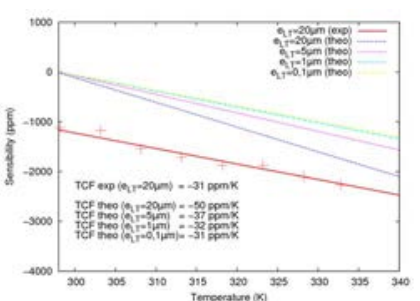

(b)
Figure 12. Frequency drift versus temperature for the isolated mode of a $50 \mu \mathrm{m}$ period device- theory/experiment assessment on a Z-cut $\mathrm{LiNbO}_{3}$ plate $(20 \mu \mathrm{m})$ (a) and a Z-cut $\mathrm{LiTaO}_{3}$ plate $(20 \mu \mathrm{m})(\mathrm{b})$

\section{CONCLUSION}

We have proposed a new acoustic resonator concept based on a periodically poled transducer $\left(\mathrm{LiNbO}_{3}\right.$ or $\left.\mathrm{LiTaO}_{3}\right)$ embedded between two silicon guiding substrates in order to create an acoustic waveguide. A resonator operating at $131 \mathrm{MHz}$ has been successfully fabricated. This resonator presents the required properties to stabilize an oscillator at this frequency. However the developed resonator presents a significant thermal sensitivity (depending mainly on PPT substrate used). The following experiments have consisted in studying a Si/thinned PPT layer/Si: monomode acoustic wave devices with an isolated mode have been successfully fabricated with a low thermal sensitivity. A thermal insensitivity is possible with an appropriate choice of guiding susbtrate. However these monomode devices do not exhibit properties compatible with oscillator requirements due mainly to technological limits to be solved. Future works consist in improving the lapping process in order to obtain a homogeneous thickness for the compact structure, studying the possibility to reduce the noise floor of the oscillator with increasing the input power of the resonator at $131 \mathrm{MHz}$ and trying to invert micrometric periods in order to achieve a $2 \mathrm{GHz}$ frequency resonator.

\section{ACKNOWLEDGMENT}

This work was supported by the french DGA (Délégation Générale pour l'Armement) under grant\#07-34-020.

\section{REFERENCES}

[1] H. Majjad, D. Gachon, V. Laude, S. Ballandras, "Interface acoustic wave devices made by indirect bonding of lithium niobate on silicon", Proc. of the IEEE US, 2006

[2] E. Courjon, J. Hauden, J. Masson, D. Gachon, L. Gauthier Manuel, W. Daniau, N. Bodin, S. Ballandras, "Pure longitudinal plate mode excited by poled domains transducers on $\mathrm{LiNbO}_{3}$ ", Proc. of the IEEE IFCS, 2007

[3] E. Courjon, J. Hauden, P. Parruch, J. Masson, D. Gachon, L. Gauthier Manuel, W. Daniau, , N. Bodin, J.M. Triscone, S. Ballandras, "Fabrication of periodically poled domains transducers on $\mathrm{LiNbO}_{3}$ ", Proc. of the IEEE IFCS, Miami, 2006

[4] S. Ballandras, W. Daniau, B. Gautier, D. Hauden, M. Wilm, V. Laude, V. Ruch, S.Flambart, "A novel surface wave transducer based on periodically poled piezoelectric domain", Proc of the IEEE EFTF-IFCS, 2003

[5] F. Bassignot, E. Courjon, G. Ulliac, T. Laroche, J. Garcia, S. Queste, JP. Romand, S. Ballandras, "An acoustic waveguide using doublybonded silicon/thinned PPT/silicon structures for RF applications", Proc. of the IEEE IUS, Rome, 2009

[6] S. Ballandras, W. Daniau, B. Gautier, D. Hauden, M. Wilm, V. Laude, V. Ruch, S.Flambart, "A novel surface wave transducer based on periodically poled piezoelectric domain”, Proc of the IEEE IFCS, 2006

[7] E. Courjon et al, "Lamb wave transducers built on periodically poled Zcut $\mathrm{LiNbO}_{3}$ wafers", Journal of Applied Physics, 102, 114107, 2007

[8] G. Kovacs, M. Anhorn, H. E. Engan, G. Visintini, C. C. W. Ruppel, "Improved material constants for $\mathrm{LiNbO}_{3}$ and $\mathrm{LiTaO}_{3}$ ". Proc. of the IEEE US, 1:435-438, 1990. 